\title{
Low-altitude Exploration of the Venus Atmosphere by Balloon
}

\author{
Geoffrey A. Landis* \\ NASA John Glenn Research Center, Cleveland, OH 44135
}

\begin{abstract}
The planet Venus represents an exciting target for future exploration by spacecraft. One target of scientific interest is the lower atmosphere, which represents an environment of high temperature and moderate to high atmospheric pressure. This represents a considerable challenge to the technical art of ballooning, but one which may be amenable to solution. Several possible designs for low-altitude balloons are discussed. Conceptual design for three mission examples are analyzed: a conventional balloon operating below the cloud level at an altitude of 25 kilometers, a large rigid-envelope balloon operating near the surface at an altitude of 5 kilometers, and a small, technology demonstrator rigid-envelope balloon operating at 5 kilometers.
\end{abstract}

\section{Introduction}

$\mathrm{T}$ HE planet Venus, Earth's nearest neighbor, is an interesting target for exploration by spacecraft. It is a planet with a carbon dioxide atmosphere that is over a hundred times more dense than the Earth's atmosphere, with unbroken layers of clouds so that the surface is never visible from space.

Many earlier missions have orbited Venus and probed the atmosphere and surface, including orbital missions, atmospheric probes, lander missions, and high-altitude atmospheric balloons. Nevertheless, significant scientific questions exist about the geology, geophysics, and the atmosphere and climate of Venus, and it remains an exceptionally interesting target for future exploration. ${ }^{1}$

Venus is, however, an exceptionally difficult target to explore, at least, at altitudes below the clouds. The thick atmosphere of Venus results in a very strong greenhouse effect, and the surface of Venus has an average temperature of about $450^{\circ} \mathrm{C}$. ${ }^{2,3,4}$ Figure 1 shows the temperature as a function of altitude above the surface. As can be seen, temperature decreases with altitude in the Venus atmosphere, and the tops of highest mountains on Venus are slightly cooler than the mean surface, but even at the highest spot on Venus (the top of Maxwell Montes, $10.4 \mathrm{~km}$ above the mean elevation), the atmospheric temperature is still $390^{\circ} \mathrm{C}$.

Adding to the difficulty of exploration is the fact that the Venus clouds consist primarily of droplets of concentrated ( $\sim 85 \%)$ sulfuric acid.

Nevertheless, despite the hostile environment, a number of missions have probed the atmosphere all the way down to the surface. These missions are the series of Russian Venera and VEGA landers, which landed on the surface and transmitted data for as long as two hours, ${ }^{2,3}$ and the American Pioneer Venus atmospheric probes, which probed the full depth of the atmosphere all the way to the surface. ${ }^{2}$

\section{A. Balloon Exploration of Venus: the VEGA mission}

One of the interesting aspects of Venus is that the thick carbon dioxide atmosphere means that atmospheric exploration, by either airplanes or balloons, is possible. The feasibility of atmospheric exploration by aircraft has been discussed in earlier papers, ${ }^{5,6}$ and is not discussed in detail here. In this paper, I will consider the use of balloons in the Venus atmosphere.

The Russian "VEGA" missions successfully demonstrated ballooning in the Venus atmosphere in 1985, the only space mission to date ever to float in the atmosphere of a planet other than Earth. The two VEGA balloons (along with two surface landers) were delivered by the Russian Halley's comet probe as it made a Venus gravity-slingshot maneuver. Two balloons were deployed into the atmosphere, and floated for 48 hours at about $54 \mathrm{~km}$ altitude.

\footnotetext{
"Physicist, Power and In-space Propulsion Division, mailstop 302-1, 21000 Brookpark Road, Cleveland OH.
} Associate Fellow, AIAA 
The VEGA balloons were 3.5-meter diameter super-pressure helium balloons. (An engineering model of the balloon is shown in figure 2) A 7-kg instrumented payload package (figure 2, inset) was carried at the end of a 13meter tether. The payload was powered by primary batteries, with instruments to measure temperature, pressure, wind speed, light intensity, and aerosol density, as well as a low-power radio transmitter and system control electronics.

The balloons were deployed and operated in the night hemisphere of Venus, which allowed the mission to be designed without thermal engineering to mitigate solar heating, and which put them on the hemisphere facing the Earth, allowing the motion of the balloons to be tracked from Earth by radio telescopes. They were deployed at an altitude of about 50 kilometers above the mean surface, and, after inflation, rose to the design equilibrium altitude of about 54 kilometers. The design altitude is at the cloud level of Venus, and was chosen to let the balloons operate at a temperature and atmospheric pressure similar to the operating conditions of balloons in the lower atmosphere of Earth. However, the conditions differed from terrestrial conditions in that the balloons were exposed to cloud droplets of high-concentration sulfuric acid. The VEGA balloon gas envelopes were fabricated from fabric of woven polytetrafluorethylene ("PTFE," more commonly known under the trade-name "Teflon"), and coated with a surface skin also of PTFE, a material which is robust against attack by sulfuric acid. (This is the shiny white skin visible on the balloon in figure 2).

This altitude is within the high-velocity "superrotation" region of the Venus atmosphere, where a constant wind moves at a velocity on the order of a hundred meters per second. This means that over the two days of the mission, the balloons traversed about $11,000 \mathrm{~km}$, from the night hemisphere into the day hemisphere. About two days into the mission, the primary batteries were depleted, and contact was lost.

As a result of the successful operation of the VEGA balloons, there have been many other proposals to fly balloons in the atmosphere of Venus, ${ }^{7,8,9,10,11}$ in order to reach a more detailed understanding of the dynamics of the Venus atmosphere. However, the VEGA balloons operated only in the relatively benign temperature regime of the cloud-level, and did not attempt to prove into the higher temperature regions below the clouds.

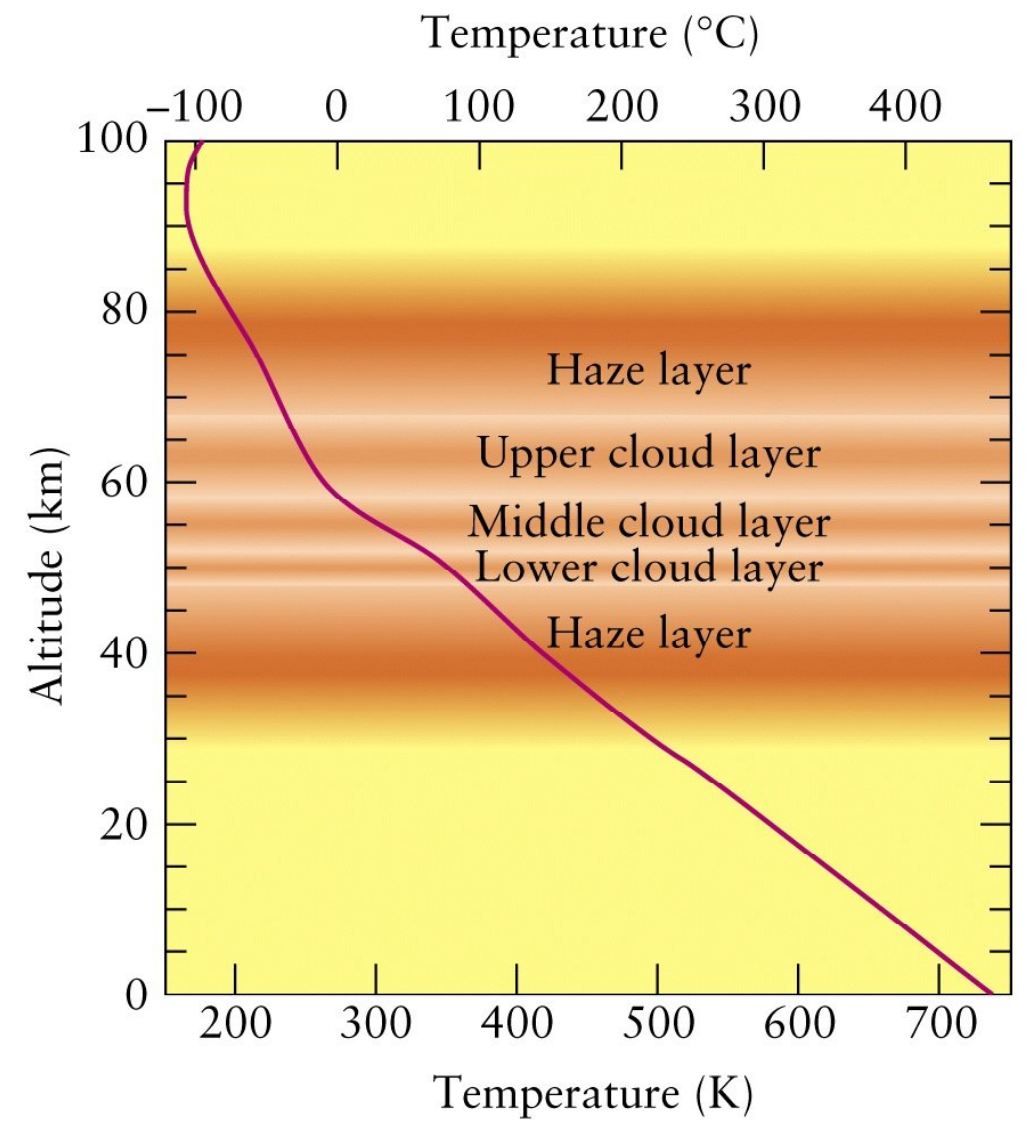

Figure 1: Venus atmosphere, showing the increase of temperature as altitude decreases, with the altitude of the cloud and haze layers marked. 


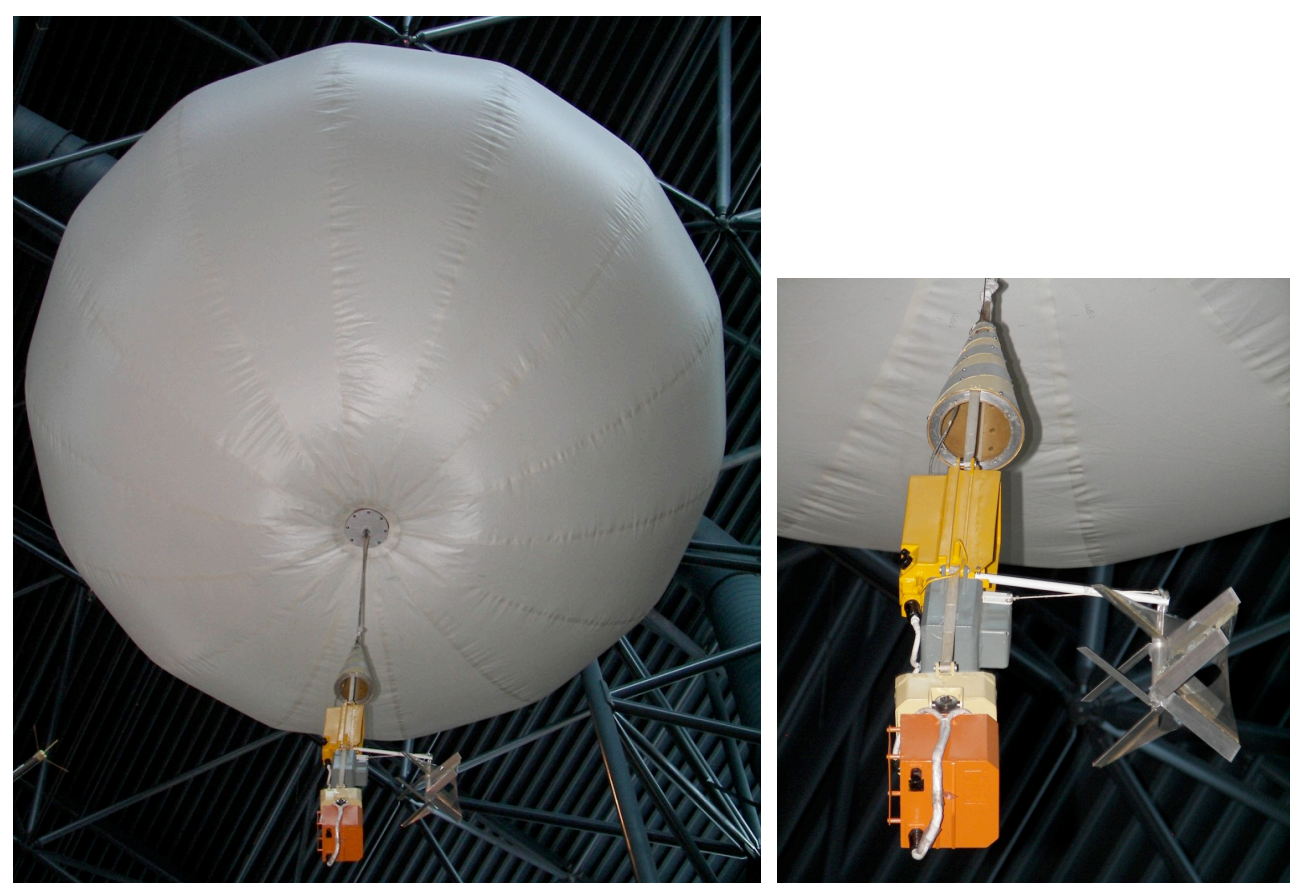

Figure 2: VEGA balloon. Left: the VEGA balloon; inset on right: mock-up of the instrument package. Images are of the VEGA Spacecraft on display at the Smithsonian Steven F. Udvar-Hazy Center (photos by Richard Kruse, 2008, used via Creative Commons Attribution-Noncommercial 3.0 United States License.)

\section{B. Future Missions: Low Altitude Exploration}

The region of the atmosphere below the clouds is also of interest to scientific exploration. There are four conceptual approaches to exploring the lower atmosphere:

\section{Drop probes.}

The only method for probing the lower atmosphere of Venus used to date has been by the use of drop probes which transit the atmosphere by falling. These probes use a parachute to slow down the initial rate of descent. However, because the atmosphere is so dense, probes used to date have jettisoned the parachute in order to transit to lower altitudes more quickly. While drop probes are a demonstrated technology, they are capable of producing only a limited duration "slice" of the atmosphere. For long duration observations requiring observations for a long time at a constant altitude (or a controllable range of altitude), drop probes are not an appropriate technology.

2. Aircraft

Another method of exploring the atmosphere is by use of aircraft. It is feasible to design an aircraft that can fly for extended durations at the cloud altitude and above. ${ }^{5,6}$ One approach to lower altitude exploration would be brief excursions by such a high-altitude aircraft diving down to lower depths. This would only allow excursions to altitudes which would not thermally stress the aircraft systems, but plausibly could allow excursions to temperatures of $200{ }^{\circ} \mathrm{C}$, and potentially even slightly lower. This would allow the observation of the altitudes below the clouds, but not the low altitudes approaching the surface. It will need technology development for altitudes below about 40 kilometers above the mean surface.

Alternatively, an aircraft could be designed for low-altitude, high-temperature operation. This would require technology development, and most notably, the development of a high power-to-weight isotope power system. The technology for this is not yet available.

\section{Balloons}

The primary difficulty for low altitude ballooning is the requirement for a high-temperature gas envelope. This is discussed in the next section, but appears to be technologically feasible

For ballooning, there is an advantage to low altitudes in that the high density of the atmosphere means that relatively small balloons sizes can carry a significant payload. 


\section{Airships}

Finally, the high density of the atmosphere at low altitudes brings up the possibility of flying an airship (that is, a powered lighter-than-air vehicle) at low altitudes. ${ }^{12}$ Since the wind velocities decrease as the surface is approached, only moderate amounts of power are required for propulsion. This will require not only a high-temperature gas envelope, but also a power system and a drive train capable of operation at high temperatures.

Although the airship concept would be an ideal exploration platform for exploration of the lower atmosphere of Venus, the technology challenges are great, and it will be examined in future work.

\section{Candidate Mission for Low Altitude Exploration}

Since the surface of Venus is never visible through the cloud layer, one mission for a low-altitude balloon on Venus is to fly at an altitude below the clouds, where the surface can be viewed. Modeling of radiative transfer in the Venus atmosphere and the camera spectral response indicates that adequate contrast can be achieved looking at the surface in near-infrared wavelengths at altitudes as high as about $16 \mathrm{~km}$, assuming a 20-deg solar zenith angle for an exposure time of $2 \mathrm{~ms}^{11,13}$ Lower altitudes allow better contrast and wider spectral range. $16 \mathrm{~km}$ corresponds to a temperature of about $613 \mathrm{~K}\left(340^{\circ} \mathrm{C}\right)$, at a pressure of 31 bars. If the mission is chosen at a location where the surface is $3 \mathrm{~km}$ above the datum, the pressure-altitude needed to achieve $16 \mathrm{~km}$ above the local surface can be increased, and the temperature decreases to $315^{\circ} \mathrm{C}$.

These are altitudes at which ballooning is difficult, but may nevertheless be feasible.

\section{Balloon Exploration}

The Russian "VEGA" mission demonstrated ballooning only at the relatively benign conditions above the cloud level, where the atmospheric pressure was below Earth sea level.

The primary difficulty for operation at lower altitudes altitude is the temperature. The first difficulty is choosing a material for the balloon envelope which can operate at elevated temperature. There are two possibilities: flexible envelopes or rigid envelopes.

\section{A. Lifting Gas}

A notable advantage of the carbon dioxide atmosphere of Venus is that this allows a much wider range of lifting gasses for a balloon; not merely the hydrogen or helium usually used for terrestrial balloons. Oxygen and nitrogen, in fact, are lifting gasses in the Venus atmosphere (although not good ones). At the altitudes considered, two other lifting gasses are water (which is a gas at the temperatures considered) and ammonia.

At the surface, the density of the Venus atmosphere is $64.8 \mathrm{~kg} / \mathrm{m}^{3}$, but at the proposed altitude of $16 \mathrm{~km}$ above the datum, the pressure of 31 bars results in an atmospheric density of $26 \mathrm{~kg} / \mathrm{m}^{3}$. At $19 \mathrm{~km}(16 \mathrm{~km}$ above a mountain plateau $3 \mathrm{~km}$ above the datum), the density decreases to $22 \mathrm{~kg} / \mathrm{m}^{3}$.

Table 1 shows the comparison of various lifting gasses at Venus for altitudes of $16 \mathrm{~km}$ and the surface.

\begin{tabular}{|l|l|l|l|l|}
\hline \multicolumn{1}{|c|}{ Gas } & $\begin{array}{c}\text { Molecular } \\
\text { weight }\end{array}$ & $\begin{array}{c}\rho / \rho_{\circ} \text { (relative } \\
\text { to } \mathrm{CO}_{2} \text { ) }\end{array}$ & $\begin{array}{c}\text { Lift at 16 } \\
\text { km }\end{array}$ & $\begin{array}{c}\text { Lift at } \\
\text { surface }\end{array}$ \\
\hline $\mathrm{CO}_{2}$ & 44 & $100 \%$ & 0 & \\
\hline $\mathrm{N}_{2}$ & 28 & $64 \%$ & $9.5 \mathrm{~kg} / \mathrm{m}^{3}$ & $23.6 \mathrm{~kg} / \mathrm{m}^{3}$ \\
\hline $\mathrm{H}_{2} \mathrm{O}$ & 18 & $41 \%$ & $15.4 \mathrm{~kg} / \mathrm{m}^{3}$ & $38.3 \mathrm{~kg} / \mathrm{m}^{3}$ \\
\hline $\mathrm{NH}_{3}$ & 17 & $39 \%$ & $16.0 \mathrm{~kg} / \mathrm{m}^{3}$ & $39.8 \mathrm{~kg} / \mathrm{m}^{3}$ \\
\hline $\mathrm{He}$ & 4 & $9 \%$ & $23.6 \mathrm{~kg} / \mathrm{m}^{3}$ & $58.9 \mathrm{~kg} / \mathrm{m}^{3}$ \\
\hline $\mathrm{H}_{2}$ & 2 & $4.5 \%$ & $24.8 \mathrm{~kg} / \mathrm{m}^{3}$ & $61.8 \mathrm{~kg} / \mathrm{m}^{3}$ \\
\hline
\end{tabular}

Table 1: Molecular weight and lifting power of various gasses at the surface of Venus and at $16 \mathrm{~km}$ above the surface.

The candidate primary lifting gas for the missions considered here is water, $\mathrm{H}_{2} \mathrm{O}$. This is chosen because it is easily carried to Venus as a liquid, but will vaporizes as temperature rises to provide pressure in lower atmosphere to pressurize the balloon provide a lifting gas. It has $70 \%$ of the lifting capability that helium would provide.

For cases where the balloon is carried to Venus in an inflated state, it is desirable that the balloon contain an additional gas to stiffen the balloon and provide interior pressurization for launch, entry and in the lowertemperature areas of the upper atmosphere. Either helium or nitrogen all be used for this purpose. Since the leak rate of helium is very high, for simplicity of operations I have assumed that nitrogen is used for this purpose.

4

American Institute of Aeronautics and Astronautics 


\section{B. Flexible Envelope Balloon}

The advantage of flexible envelopes is that the envelope can be folded and stowed in a relatively small volume for transport, and inflated to large volume. The envelope must have no major leaks against gas loss, although pinhole-sized flaws in the envelope are not significant, since the time for significant gas leakage through a pinhole flaw is likely to be longer than the mission duration. For conventional (flexible envelope) balloon, a proposed polymer material available for gas containment would be a high-temperature polyimide. Currently available hightemperature polyimides lose strength at temperatures above $\sim 350^{\circ} \mathrm{C}$, and thus the expected strength would be marginal at best at the desired operating altitude.

In order to provide the mechanical strength, a second layer is used which is mechanically strong, but not gastight. The baseline approach would be to use a woven carbon fiber cloth for the high temperature mechanical strength. Layered onto this would be a corrosion barrier (to prevent chemical attack). A candidate barrier would be a two layer gold / silicon-dioxide film.

The temperature at the 16 -kilometer altitude for the nominal mission is $340^{\circ} \mathrm{C}$. This is very close to the upper bound on temperature achievable with a polymer envelope, and thus $16 \mathrm{~km}$ is nearly the lower bound on achievable altitude.

To use a balloon at lower altitudes would probably require a metal envelope.

\section{Rigid Balloon}

\section{Overview of Rigid Metal Balloon Concept}

The lack of flexibility of a metal envelope means that is not easily possible to stow the metal envelope in the deflated state. The proposal, then, would be that the gas envelope launches from Earth, cruises to Venus, and enters the atmosphere in an already-deployed state.

Atmospheric entry is easiest for objects which have low density, in order to achieve a low ballistic coefficient (i.e., high surface area per unit weight). This is relatively easy for a balloon, and in fact entry in the deployed state will require a high temperature material such as titanium.

An example of a rigid envelope balloon would be a titanium sphere optimized for strength to weight ratio \& thermal performance, with a gold coating to prevent corrosion, and a final silicon or titanium-dioxide film coating designed to maximize the infrared emissivity. The envelope would be run with the interior pressure equal to the exterior pressure at mission altitude (i.e., a "zero pressure balloon").

The rigid envelope balloon has the feature that it is already at its full volume during launch, cruise, and atmospheric entry. The advantage of this feature is that it does not need deployment in the atmosphere, thus removing one failure mechanism. A spherical entry shell at low ballistic coefficient has extremely good entry dynamics, and a titanium shell would have extremely good thermal properties. A primary limitation on such a balloon would be the launch limitation, set by the requirement that the diameter must be less than the interior diameter of the booster vehicle launch shroud, since it must fit inside the shroud, fully inflated, during launch. There is, in fact, no requirement that the balloon must be spherical, and a larger interior volume could very likely be achieved with a non-spherical balloon; however, since a non-spherical balloon is difficult to analyze, this has not been considered here.

\section{Atmospheric Entry}

The metal balloon must be designed to enter the atmosphere without damage. There is a good theoretical (and experimental) design base of spherical entry bodies, ${ }^{14,15}$ so this analysis is relatively straightforward. As the ballistic coefficient (defined as mass per unit cross-sectional area) decreases, the altitude of peak entry deceleration increases, and hence (since the deceleration occurs at a lower atmospheric density), the heating rate is decreased. For a sphere, the entry-heating rate decreases as the square root of the radius, and the square root of the ballistic coefficient. If the object is in radiating, the area over which entry heat is radiated is proportional to the radius squared, and hence the temperature required to radiate a given amount of power decreases as $1 / \mathrm{r}^{2}$. Thus, the larger the radius, the lower the temperature reached during entry. Balloons, being necessarily lightweight yet with high surface area, are ideal for atmospheric entry. We will require that the entry-heating rate be low enough that the entry heat can be radiated away, rather than ablated, and thus we want to keep the maximum entry temperature below the melting point of the material.

The entry energy to be dissipated is

$$
\mathrm{E}=1 / 2 \mathrm{~m}\left(\mathrm{Ve}^{2}+\mathrm{V} \infty^{2}\right)
$$


where $m$ is the entry mass, Ve the escape velocity of Venus, $10.46 \mathrm{~km} / \mathrm{sec}$, and $\mathrm{V} \infty$ the hyperbolic excess velocity (which will be negative if the balloon enters from orbit). Clearly, the energy to be dissipated depends on whether the probe enters directly from the interplanetary trajectory, or is captured into orbit.

The calculations detailed in reference [15] show that large-diameter hollow spheres of titanium have no difficulty surviving atmospheric entry. It is, in fact, experimentally demonstrated that a titanium sphere can enter the atmosphere without burning through. Figure 3 shows an example of a spherical titanium helium tank recovered after entering the atmosphere.
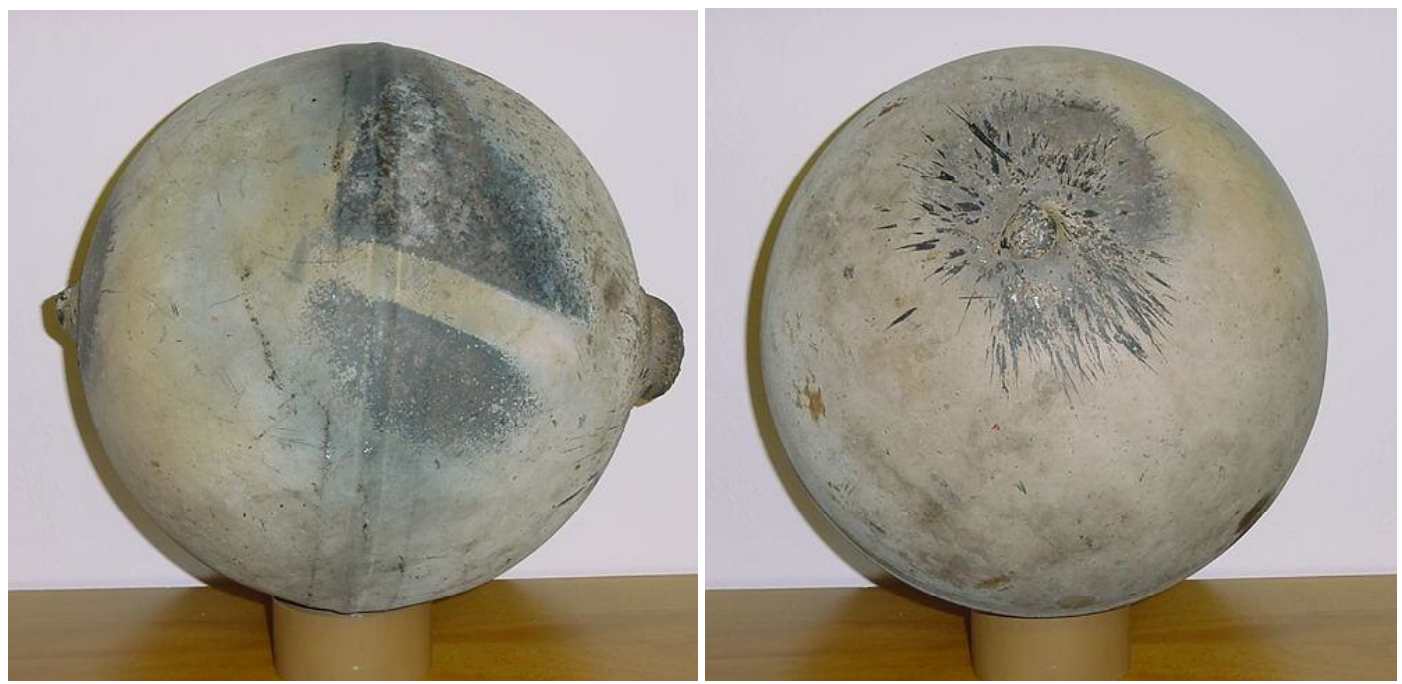

Figure 3: A 36-cm titanium helium tank from the Salyut 7 / Kosmos 1686 mission, recovered after atmospheric reentry in $1991 .{ }^{16}$

\section{Metal Bellows Balloon}

A possible technology which combines the advantages of flexible envelope balloon with the high-temperature capability of a rigid metal envelope is the "metal bellows" balloon design. This is a design has been proposed by teams at JPL for use as a launch system to take a sample from the surface to a higher altitude. ${ }^{17}$

\section{Technologies for Low-Altitude Exploration}

Although it is primarily the intent of this paper to examine the feasibility of the overall concept of a low-altitude balloon, and not examine the individual technologies needed for system operation, it is worth pointing out that the technologies for operation of the spacecraft system in the high temperature environment are not trivial. Several references, including Landis (2006) ${ }^{18}$ and Kolawa $(2007)^{19}$ look at the technologies (in the context of missions to land on the Venus surface) in more detail.

\section{A. Power System}

All missions require power, which is needed to operate the command and control system, make observations with the scientific instruments, and power the radio communications system that sends the data back to the scientists on Earth. Most conventional power system technologies are not capable of operation at Venus temperatures, although it is plausible for very-short duration missions to accept a power system that they will only be able to operate for a short period, until it reach equilibrium temperature with the environment (possibly with the benefit of thermal mass or phase-change materials designed to slow down rate of heat rise). For an extended mission, however, it is necessary to use a power system capable of operating at higher temperature.

There are several approaches to a power system capable of operating in the high-temperature environments seen by a low-altitude balloon. The main approaches are (1) use conventional power system technologies, and incorporate a cooling system to keep the system from exceeding operating temperatures, or (2) use technologies designed to survive the Venus environment. In the first approach, the cooling system itself represents an additional load for the power system. 
For missions that are either low power, or relatively limited in duration, it is possible to use primary batteries as the power system. It is a fortuitous fact that battery systems can be found that operate at Venus temperatures. A review of battery technology for Venus can be found in references [19] and [20]. Most notably, sodium-sulfur batteries produce high specific power, comparable or better than other battery chemistries used for space, and operate well at the Venus lower atmosphere temperature. ${ }^{20}$

Another more conventional approach to power for spacecraft is to use solar cells. Unfortunately, solar cells work poorly in the environment below the clouds on Venus. Three factor reduce the performance: ${ }^{21}$ first, solar cells decrease in performance as temperature increases; second, the thick cloud layers results in relatively low light intensity below the clouds, and finally, light scattering by the atmosphere reduces the intensity preferentially in the blue, which is the spectral region in which high-temperature solar cells are most responsive. Nevertheless, analyses show that solar cells are expected to retain some performance even at the temperature range found down to the surface, although the encapsulation technology for operation of solar cells at these temperatures has yet to be demonstrated. The performance at the surface is relatively low, with an estimated area of about 1.2 square meters required to produce one watt of power. ${ }^{21}$ This may be acceptable to power extremely small science packages. At an altitude of $10 \mathrm{~km}$ above the surface, the required area for a watt of power reduces to about 0.4 square meters.

An alternative for higher power levels for long-duration missions is to use an isotope power supply. This has been proposed for Venus surface missions. ${ }^{22,23,24}$ Most likely would be a power system using a radioisotope Stirling power system based on the Advanced Stirling Radioisotope Generator (ASRG) technology. ${ }^{23,25}$ The ASRG has a mass of $20.2 \mathrm{~kg}$ per converter, and a power output of 160 Watts, assuming it is run at the advanced-technology hotend temperature of $850^{\circ} \mathrm{C}$. The power output must be downrated, however, because of the higher temperature of the heat rejection temperature, about $450^{\circ} \mathrm{C}(723 \mathrm{~K})$, rather than the nominal (lower) heat rejection temperature. This reduces the Carnot efficiency, and hence reduce the actual power produced by about a factor of two compared to the nominal power. This would result in a power output of about 80 watts per ASRG unit.

In addition, power must be used to run cooling units. ${ }^{26}$ This power, and weight of the power system to product this power, must also be accommodated in the design.

\section{B. Instruments and Control Systems}

The gas envelope and power system is only a small part of the systems that need to operate at high temperature. It is also necessary that the electronic systems be designed for operating in the Venus environment. Down to an altitude of about 21 kilometers, it may be possible to use conventional electronics, but below this altitude, the operating temperature is too high to use conventional approaches without cooling. Approaches to the electronics and instruments would be to either use advanced, high-temperature electronics and sensor technologies that continue to operate at the temperatures of interest, ${ }^{27,28}$ or to use cooling system to keep electronics and other systems at a usable operating temperature. ${ }^{22,26}$

Both approaches have been analyzed for Venus surface systems. ${ }^{18.19}$

\section{Mission Design Examples}

\section{Example Design: 2-meter Flexible Balloon}

For the first design example, we will look at the case of an atmospheric science mission designed to float at a target altitude just below the clouds.

For this mission we will assume uncooled conventional electronics. The lowest altitude achievable will be set by the thermal limit of conventional silicon electronics, since at the moment there are no replacements for silicon (computer) microchips for controllers. The highest operating-point existing microcontroller ${ }^{29}$ has a maximum limit to demonstrated operating temperature of $300^{\circ} \mathrm{C}$. This corresponds to $21 \mathrm{~km}$ altitude on Venus. To leave margin, the baseline altitude for this mission will be to operate at a design altitude of $25 \mathrm{~km}$. Thus, this mission will probe the mostly-unknown atmospheric region well below the clouds. At this altitude, the temperature is $265^{\circ} \mathrm{C}$, pressure $15 \mathrm{bar}$, and density $14.6 \mathrm{~kg} / \mathrm{m}^{3}$ (almost 12 times Earth's sea-level density).

The 25 kilometer altitude is not low enough to achieve the discussed mission of observing the surface in the infrared, however, it nevertheless would represent a region in which we can make atmospheric measurements in a new level of the Venus atmosphere that has, to date, only been traversed for short periods by probes falling downward toward the surface, but not yet been observed for an extended period.

As noted in the previous section, this altitude can be achieved with a conventional flexible-envelope balloon. The technology chosen is a mechanical balloon envelope from carbon-fiber mesh cloth, with a polymer gascontaining layer. The operating temperature is below the highest recommended operating temperature of $288^{\circ} \mathrm{C}$ for 
PTFE ("Teflon"). This will allow the gas-containing polymer to also be the outer corrosion barrier of PTFE film, which is impervious to attack by sulfuric acid. (Note that the balloon operation level will in fact be below the region of sulfuric acid droplets, and the reactive agents in the atmosphere will instead be anhydrous sulfuric acid (sulfur trioxide) and possibly hydrogen sulfide).

The mass of the envelope material, including both the carbon fiber cloth and the PTFE envelope, is assumed to be 100 grams per square meter.

Payload for the mission will be atmospheric science, consisting of meteorology (temperature, pressure, light intensity and spectrum), atmospheric motion (inertial guidance unit to measure motion, plus an ultrastable oscillator to allow precision tracking), and atmospheric composition (nephelometer, mass spectrometer). Target mass for the scientific payload is $15 \mathrm{~kg}$, with an additional 10 kilograms allocated to support electronics, telecommunications, and structure, for a total payload of $25 \mathrm{~kg}$, similar to the $22.5 \mathrm{~kg}$ payload proposed for the Venus Design Reference mission (VDRM) balloon of the Venus Flagship mission. ${ }^{10,11}$ The average power allocated will be 100 Watts.

The power system for this mission will be a photovoltaic array. The zonal wind at this altitude, as measured by the Pioneer probes, ${ }^{3}$ ranges from 10 to 40 meters per second, or 860 to $3500 \mathrm{~km}$ per (Earth) day. The balloon will thus be expected to traverse the sunlit hemisphere in a time between 5.5 and 22 days. Thus, without incorporating energy storage to allow the probe to operate during night, the mission will be planned for a minimum expected mission duration of 5 days.

At this altitude, accounting for the solar intensity, spectral shift, and the temperature, following the calculation of reference [21] high-efficiency triple-junction solar cells are expected to produce an output power of about 140 $\mathrm{W} / \mathrm{m}^{2}$. A solar panel area of 0.71 square meters will thus be sufficient to power the probe when the sun is near zenith during the daylight portion of the mission. Allowing for operation at lower sun angles, 2.5 square meters of solar array area are assumed. This solar array is estimated to have a mass of $10 \mathrm{~kg}$. The total mass of the payload, including power system, is assumed to be $35 \mathrm{~kg}$.

Since the operating temperature is well above the vapor point of water, for simplicity of the system, the lifting gas is assumed to be water vapor.

From the weights given, the required balloon diameter is 2 meters. This is a little more than half the diameter of the balloon for the VEGA mission, despite the considerably higher payload, due to the much denser atmosphere at this level. At this size, the balloon envelope itself has a mass of $1.25 \mathrm{~kg}$, and the mass of the lifting gas, assumed to be water, is $25 \mathrm{~kg}$. The total mass of the probe, including the payload, balloon, and the water to pressurize the interior, equals the mass of the Venus atmosphere displaced by the balloon, $61 \mathrm{~kg}$.

\section{Example Design: 3.8 meter balloon with quarter-ton payload}

The candidate mission design for the second example is to fly at an altitude low enough that the surface can be viewed in near-infrared. Although this can be done at altitudes as high as about $16 \mathrm{~km}$, lower altitudes allow much better viewing, and hence an altitude as low as possible will be analyzed.

As a design example of such a rigid metal-sphere balloon, consider a balloon designed to float at a target altitude of $5 \mathrm{~km}$. At this altitude, the atmospheric density is roughly $50 \mathrm{~kg} / \mathrm{m}^{3}$ and the temperature $425^{\circ} \mathrm{C}$. At this altitude, the mission cannot operate with ambient temperature electronics, and hence the electronics will be cooled.

The balloon diameter is set by the launch shroud. This allows a rigid balloon to have to have a maximum diameter of $<3.8$ meters, assuming a Delta-IV 4-m shroud, or up to 4.8 meter (if the shroud is changed to a DeltaIV Medium-plus or Heavy shroud). The example design will assume the more conservative 1.8-meter diameter.

Figure 4 shows the conceptual design. For a balloon with a 3.8-meter diameter the interior volume is $28 \mathrm{~m}^{3}$, and hence the atmospheric displacement, at $50 \mathrm{~kg} / \mathrm{m}^{3}$, is $1430 \mathrm{~kg}$. The $2-\mathrm{mm}$ thick titanium shell has a mass $410 \mathrm{~kg}$, and an additional amount of $100 \mathrm{~kg}$ is allocated for added structure needed to distribute the load.

Verifying against the entry calculations for titanium spheres of Fritsche, Lips, and Koppenwallner, ${ }^{15}$ this is nearly a factor of two lower mass than the mass at which entry heating approaches the melting point of titanium. Hence, atmospheric entry is not expected to be a problem.

The lifting gas inside the balloon is a mixture of nitrogen plus water. The nitrogen is used to keep the balloon pressurized during launch, entry and passage through the upper atmosphere. The water vaporizes as the external temperature rises, to provide internal pressure in lower atmosphere. The nitrogen is pressurized at 2 atmospheres at launch; resulting in 5 atmospheres at $425^{\circ} \mathrm{C}$ operating temperature, and so the nitrogen pressurant mass is $70 \mathrm{~kg}$. The water vapor provides the rest of the pressure, with pressurant mass of $530 \mathrm{~kg}$. This gives a total balloon mass of $1110 \mathrm{~kg}$, allowing a maximum payload mass of $320 \mathrm{~kg}$.

Power for the mission will be provided by four radioisotope generators, with technology based on the ASRG technology, ${ }^{23,25}$ adapted with a higher heat-rejection temperature for Venus operation. An added mass margin of $50 \%$ is added to account for any modification needed to adapt the ASRG to Venus temperature. The power system 
paper 2010-628, 48th AIAA Aerospace Sciences Meeting, Orlando FL, January 6-9 2010.

mass is $150 \mathrm{~kg}$, and will produce a total power output of 320 Watts under operating conditions. It is assumed that, of this, 200 watts will be used to run a cooling system to keep the primary electronic and sensors at operating temperature. The details of the cooling system will not be analyzed here, however, a number of choices are available, including Stirling coolers which have already been demonstrated in flight experiments, as well as more conventional cycles of refrigerators, or all-electronic Peltier coolers. This gives a power availability of 120 watts to run the payload and instruments.

The cooled electronics enclosure is pressurize-equalized to the Venus ambient pressure, using a HFC-236a halocarbon as the pressurant gas. ${ }^{18}$ This is a pressurant used for fire suppressant, with a low thermal conductivity.

After subtracting the power system, the available mass for the payload is $170 \mathrm{~kg}$. In additional to the science instruments, this must include all the systems for operation, including controls, telecommunication system, the cooling systems, and any added structural mass, include the insulated compartment for the cooled electronics.

It is worth noting that the $5 \mathrm{~km}$ altitude is measured with respect to the datum, and is not necessarily the altitude above the surface. At this altitude, depending on the site chosen, the balloon could be at any altitude from zero to eight kilometers above the actual surface. The example has been for a $5-\mathrm{km}$ altitude, however, this is not an inherent limit to the technology. Higher altitudes will reduce the payload due to the decrease in density; and conversely, decreasing the altitude toward the surface will increase the allowed payload.

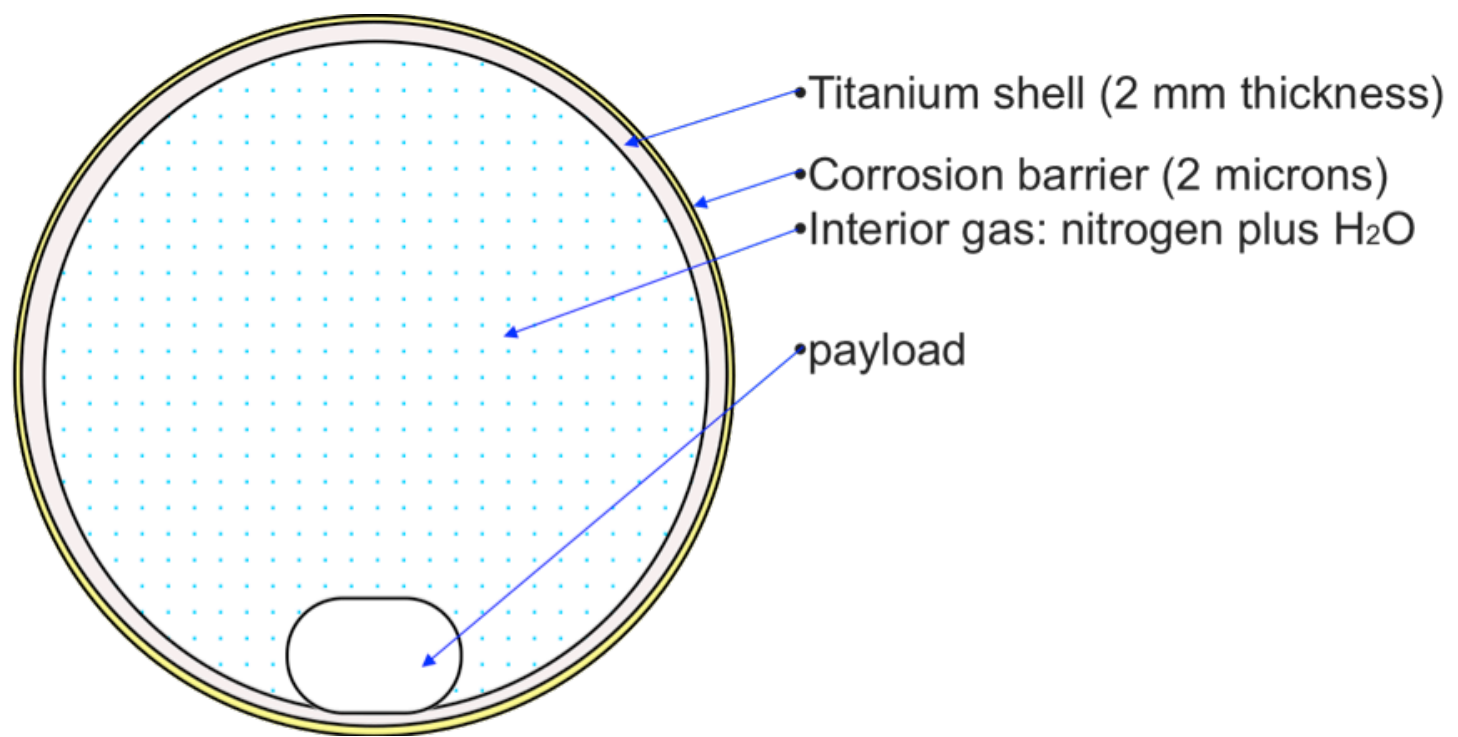

Figure 4: Conceptual sketch of metal shell balloon

\section{Example Design: 2 meter balloon with 35-kg payload}

The previous calculation was for a relatively large mission. It is also of interest to examine the case of a mission at the same altitude, $5 \mathrm{~km}$, but with a much smaller balloon, fitting in a smaller launch vehicle, and hence presumably achievable at a lower cost. The primary mission will be as a technology demonstration mission, showing that components and system are functional in the Venus environment, and the goal is to be a low-cost mission, perhaps as a "hitch-hiking" additional payload on a Discovery class mission to Venus.

For this smaller mission we will not assume an isotope power system, but instead will chose a sodium-sulfur primary battery, which can operate at the temperatures of interest. ${ }^{20}$ The mission will operate uncooled, utilizing high-temperature electronics. ${ }^{19,27}$ The requirement for electronics that can operate at $425 \mathrm{C}$ restricts the range of missions, since computer control is not possible with existing technology, and the sensors will be restricted to minimum. The primary mission will incorporate real-time data relay, with no electronic data storage, and the measurements will be a restricted set of meteorological data. The position of the balloon will be measured by analysis of the radio transmission, and thus the motion of the balloon (and thus the local wind regime) will be measured. Although no provision is made to cool the entire electronics package, a small cooled enclosure with a Peltier cooler will be provided in order to cool the focal plane of a camera, so that images of the surface can be made for Public Relations purposes. 
paper 2010-628, 48th AIAA Aerospace Sciences Meeting, Orlando FL, January 6-9 2010.

For the small balloon, we will assume a thinner $(1 \mathrm{~mm})$ metal shell. In this case, the balloon diameter is 2 meters, and the volume is $4.2 \mathrm{~m}^{3}$. Again, the thin skin (and hence low ballistic coefficient) results in this shell being well below the mass at which entry heating will be a problem.

The 2-meter diameter balloon gives an atmospheric displacement (at $\left.50 \mathrm{~kg} / \mathrm{m}^{3}\right)$ of $210 \mathrm{~kg}$. For this case, the shell mass is $57 \mathrm{~kg}$, and I assume additional load-bearing structure of half the shell mass, $28 \mathrm{~kg}$.

Assuming an interior pressure of 2 bar of nitrogen at launch ( 5 bar at the operating altitude), the nitrogen mass is $10 \mathrm{~kg}$. The remainder of the pressurization is done with water vapor, with the total mass of water $80 \mathrm{~kg}$. Thus, the total balloon mass is $175 \mathrm{~kg}$, allowing a maximum payload of $35 \mathrm{~kg}$.

\section{Conclusion}

Ballooning in the lower atmosphere of Venus is a difficult challenge. Several possible approaches have been outlined. Three concepts for balloon operation were analyzed and shown to be feasible at the conceptual-design level: a conventional flexible-envelope balloon operating below the cloud level at an altitude of 25 kilometers, a large rigid-envelope balloon operating near the surface at an altitude of 5 kilometers, and a small, technology demonstrator rigid-envelope balloon operating at 5 kilometers.

\section{Acknowledgments}

An earlier version of this work was presented at the Venus Exploration Science and Technology Definition Team (STDT) meeting, Washington, DC, May 5, 2008. Portions of this analysis were incorporated as chapter 5.4.1.4, "Low Altitude Balloons," of the Science and Technology Definition Team Report.

\section{References}

1. Space Studies Board, New Frontiers in the Solar System: An Integrated Exploration Strategy, National Academies Press, Washington DC, 2003

2. D. M. Hunten, L. Colin, T. M. Donahue, and V. I. Moroz, Venus, University of Arizona Press, Tucson AZ, 1983.

3. S. W. Bougher, D. M. Hunten, and R. J. Phillips, Venus II, University of Arizona Press, Tucson AZ, 1997.

4. J. B. Pollack, "Atmospheres of the Terrestrial Planets," The New Solar System, 3rd Edition, Beatty and Chaikin (eds.), Cambridge University Press, Cambridge, pp. 91-103, 1990.

5. G.A. Landis, C. Lamarre, and A. Colozza, "Venus Atmospheric Exploration by Solar Aircraft," Acta Astronautica, Vol. 56, No. 8, pp. 750-755, April 2005.

6. G.A. Landis, C. LaMarre and A. Colozza, "Atmospheric Flight on Venus: A Conceptual Design," Journal of Spacecraft and Rockets, Vol 40, No. 5, pp. 672-677, Sept-Oct. 2003.

7. M. S. Smith, R. S. Schallenkamp, C. J. Ekstein and K. Blizard, "Development of Venusian Aerobots," paper AIAA-97-1446 (1997).

8. M.S. Gilmore et al., "Investigation of the Application of Aerobot Technology at Venus," Acta Astronautica, Vol. 56, pp 477-494, 2005.

9. K.H. Baines, et al., "Nuclear Polar VALOR: An ASRG-Enabled Venus Balloon Mission Concept", AGU Fall Meeting, Paper number: P33A-1439, December 15-19 2008.

10. M.A. Bullock, et al., A Venus Flagship Mission: Report of the Venus Science and Technology Definition Team," 40th Lunar and Planetary Science Conference (Lunar and Planetary Science XL), The Woodlands, TX, March 23-27, 2009.

11. Venus Science and Technology Definition Team, Venus Flagship Mission Study: Final Report of the Venus Science and Technology Definition Team, NASA, April 2009.

12. A. Colozza, Airships for Planetary Exploration, NASA CR-2004-213345, November 2004.

13. M. A. Bullock and D. H. Grinspoon, "Climate change on Venus and future spacecraft mission priorities," COSPAR, Vol. Abstract COSPAR02-A-02662, Houston, Texas, 2002.

14. C. Gazley and D. J. Mason, "A Recoverable Scientific Satellite," Project Rand Research Memorandum RM- 
1844, Dec. 21, 1956.

15. B. Fritsche, T. Lipsa and G. Koppenwallner, "Analytical and numerical re-entry analysis of simple-shaped objects," Acta Astronautica, Vol. 60, No. 8-9, April-May 2007, pp. 737-751.

16. G. A. Graham, et al., "Analysis of Impact Residues on Spacecraft Surfaces: Possibilities and Problems," 3rd European Conference on Space Debris, 19 - 21 March 2001, Darmstadt, Germany

17. V.V. Kerzhanovich, J. Hall, A. Yavrouian and J. Cutts, "Two Balloon System to Lift Payloads for the Surface of Venus," paper AIAA-2005-07322, AIAA 5th ATIO and 16th Light-Than-Air Systems, Tech. and Balloon Systems Conferences, Arlington, Virginia, Sept 26-28, 2005; see also Lunar and Planetary Science XXXVI, abstract 1223 (2005).

18. G.A. Landis, "Robotic Exploration of the Surface and Atmosphere of Venus," Acta Astronautica, Vol. 59, No. 7 , pp. 517-580, October 2006.

19. E. Kolawa et al., Extreme Environment Technologies for Future Space Science Missions, Technical Report JPL D-32832, National Aeronautics and Space Administration, Washington DC (2007).

20. R. Harrison and G. Landis, "Batteries for Venus Surface Operation," paper AIAA-2008-5796, presented at the 6th AIAA International Energy Conversion Engineering Conference, Cleveland OH, July 28-30, 2008.

21. G. Landis and T. Vo, "Photovoltaic Performance in the Venus Environment," 34th IEEE Photovoltaic Specialists Conference, Philadelphia PA, 7-12 June 2009.

22. G. Landis and K. Mellott, "Venus Surface Power and Cooling System Design," Acta Astronautica, Vol 61, No. 11-12, 995-1001 (Dec. 2007). Presented as paper IAC-04-R.2.06, 55th International Astronautical Federation Congress, Vancouver BC, Oct. 4-8 2004.

23. K. D. Mellott, "Power Conversion with a Stirling Cycle for Venus Surface Mission," paper AIAA-2004-5633, AIAA 2nd International Energy Conversion Engineering Conference, August 16-19 2004, Providence, RI.

24. J. Chan, J.G. Wood, and J.G. Schreiber, "Development of Advanced Stirling Radioisotope Generator for Space Exploration," Proceedings of Space Technology and Applications International Forum (STAIF-2007), edited by M.S. El-Genk, AIP Conference Proceedings 880, pp. 615-623, 2007.

25. J.G. Wood, et al., “Advanced Stirling Convertor (ASC) Phase III Progress Update,” Proceedings of Space Technology and Applications International Forum (STAIF-2007), edited by M.S. El-Genk, AIP Conference Proceedings 880, pp. 313-324, 2007.

26. K. D. Mellott, "Electronics and Sensor Cooling with a Stirling Cycle for Venus Surface Mission," paper AIAA2004-5610, AIAA 2nd International Energy Conversion Engineering Conference, August 16-19 2004, Providence, RI.

27. P. G. Neudeck and R. S. Okojie, "High-Temperature Electronics-A Role for Wide Bandgap Semiconductors?" Proceedings of the IEEE, Vol. 90, No. 6, pp. 1065-1076, June 2002.

28. F. P. McCluskey, R. Grzybowski, and T. Podlesak, eds., High Temperature Electronics, CRC Press 1997.

29. Data sheet, 83C52 High Temperature Microcontroller, 900141 Rev. B (4/98). See: http://www.alldatasheet.com/datasheet-pdf/pdf/82436/HONEYWELL/HT83C51.html 